\title{
Partição de recursos florais de espécies de Sida Linnaeus e Malvastrum coromandelianum (Linnaeus) Garcke (Malvaceae) entre Cephalurgus anomalus Moure \& Oliveira (Hymenoptera, Andrenidae, Panurginae) e Melissoptila cnecomala (Moure) (Hymenoptera, Apidae, Eucerini)
}

\author{
Elder Ferreira Morato ${ }^{1}$ \\ Lúcio Antônio de O. Campos ${ }^{2}$
}

\begin{abstract}
Floral resource partitioning on Sida Linnaeus and Malvastrum coromandelianum (Linnaeus) Garcke (Malvaceae) between Cephalurgus anomaIus Moure \& Oliveira (Hymenoptera, Andrenidae, Panurginae) and Melissoptila cnecomala (Moure) (Hymenoptera, Apidae, Eucerini). The flowering pattern and the visiting bee species on Sida spp. and Malvastrum coromandelianum (L.) Garcke were studied in a restricted area at the campus of the Universidade Federal de Viçosa, Minas Gerais, Brazil. There were differences among plant species but not among individuals in relation to the flowering time along the day and the time at which the flowers were visited by bees. Melissoptila cnecomala (Moure, 1944) and Cephalurgus anomalus Moure \& Oliveira, 1962 were the most frequent visitors. Both species foraged on flowers for nectar and pollen. $C$. anomalus visited mainly plants with anthesis in the morning and $M$. cnecomala plants with anthesis in the afternoon. This fact sugests that those species of bees may be showing contrasting foraging strategies and can share the floral resources of Sida and Malvastrum. The males of $C$. anomalus mate on flowers of Sida and exhibit a behavior known as rendevouz pollination. KEY WORDS. Malvaceae, Sida, Malvastrum, bees, resource partitioning
\end{abstract}

As abelhas são dependentes das flores para a obtenção de alimento (néctar, pólen, óleo) e outros recursos tais como fragrâncias, resinas, tricomas florais e calor (WILLIAMS \& DODSON 1972; SIMPSON \& NEFF 1981). As flores podem servir como local para cópula e repouso para algumas espécies de abelhas (FAEGRI \& VAN DER PIJL 1979; SIMPSON \& NEFF 1981). O fato das abelhas serem, de modo geral, eficientes promotores de polinização cruzada e as vantagens genéticas desse sistema de reprodução (FAEGRI \& VAN DER PIJL 1979; CREPET 1983; BUCHMANN \& NABHAN 1996) para as angiospermas, torna essa associação uma relação de benefício mútuo.

Os recursos florais disponíveis numa comunidade podem ser fatores limitantes, ocasionando competição entre as espécies de polinizadores (JOHNSON \& HUBBELl 1974; RouBIK 1978; INOUYE 1978; RouBIK 1981, 1982; BUCHMANN 1996). A coexistência dessas espécies na comunidade só é possível mediante o

1) Pós-Graduação em Ecologia Conservação e Manejo de Vida Silvestre, ICB, Universidade Federal de Minas Gerais. 30161-970 Belo Horizonte, Minas Gerais, Brasil.

E-mail: morato@dedalus.lcc.ufmg.br

2) Departamento de Biologia Geral, Universidade Federal de Viçosa. 36570-000 Viçosa, Minas Gerais, Brasil. E-mail: Icampos@mail.ufv.br 
emprego de diferentes estratégias de forrageamento (JOHNSON \& HUBBELL 1975; HEINRICH 1976a; JoHNSON 1983). Por outro lado, limitações na quantidade de polinizadores podem resultar em competição entre espécies de plantas e diminuição na produção de sementes (RATHCKE 1983; ZIMMERMAN 1984; CAMPBELL 1985a, 1986; NeFF \& SimPSON 1993; Allen-W ARdell et al. 1998). A coexistência dessas espécies só é possível mediante o emprego de diferentes estratégias de utilização de polinizadores (Pleasants 1980; KePHART 1983).

Para as espécies de polinizadores, pelo menos, três estratégias são teóricamente possíveis e garantiriam o acesso aos recursos florais disponíveis em uma comunidade: os polinizadores podem forragear em diferentes espécies de plantas (Pleasants 1980); podem explorar o recurso em diferentes horas do dia ou diferentes períodos de uma estação (GINSBERG 1983); podem forragear em diferentes manchas de recurso, seja quanto à distribuição espacial (CARPENTER 1979) ou à densidade do mesmo nas manchas (JoHnSON \& HuBBELL 1975; GINSBERG 1983).

Para as espécies de plantas, a polinização poderia ser assegurada por, pelo menos, três estratégias: uso de diferentes espécies de polinizadores (PLEASANTS 1980); floração em diferentes horários ou épocas do ano (HEINRICH \& RAVEN 1972; HEINRICH 1976b; LACK 1982a,b,c; BAWA 1983; CAMPBELL 1985b); oferecimento de diferentes tipos de recursos florais (HEINRICH \& RAVEN 1972).

Competição entre plantas por polinizadores e competição entre polinizadores por recursos florais devem ocorrer de forma dinâmica e complementar. ROUBIK \& BUCHMANN (1984) sugerem que, durante um dia ou período de tempo maior, as interações competitivas entre plantas e visitantes florais são inversas: quanto maior for a quantidade de recursos florais, menor será a competição entre os polinizadores e quanto maior a quantidade de polinizadores, menor será a competição entre plantas.

Assim, as interações entre as plantas floríferas e seus polinizadores desempenham um importante papel na determinação da estrutura de suas comunidades (Heithaus 1974, 1979a,b; RANTA et al. 1981; RANTA 1982; FeInSINGER 1987).

O gênero Sida Linnaeus compõe-se de plantas perenes, anuais e bianuais, de porte herbáceo e sub-arbustivo, folhas simples, inteiras, alternas e estipuladas; flores hermafroditas, solitárias ou em inflorescências; carpídios trígonos e deiscentes na maturação (LEITÃo FILHO et al. 1982). Segundo FRYXELL (1988) esse gênero possui aproximadamente 150 espécies que ocorrem nas Américas, África, Ásia e Austrália. São consideradas plantas daninhas. Contudo, plantas de algumas espécies possuem propriedades medicinais e são boas produtoras de fibras (MONTEIRO-FILHO 1936; LORENZI 1982).

O gênero Malvastrum A. Gray também é composto de plantas invasoras, anuais ou perenes, herbáceas e sub-arbustivas, sendo muito comuns na região Centro-sul de nosso país (LORENZI 1982). Segundo FRYXELL (1988) esse gênero possui cerca de 14 espécies com distribuição nas Américas, principalmente. $M$. coromandelianum (L.) Garcke possui distribuição pantropical, mas pode atingir as regiões temperadas. Esta espécie possui folhas lanceoladas, alternas, pecioladas e estipuladas; flores axilares, solitárias e hermafroditas; carpídios papiráceos, com uma arista apical (LEITÃo FILHO et al. 1982). 
GOTTSBERGER (1972) refere-se a M. coromandelianum e às espécies de Sida por ele estudadas como autógamas facultativas.

GotTSBERGer (1986) refere-se a Sida e Malvastrum como autógamas. Segundo esse autor, a melitofilia aparentemente tornou-se preponderante entre as Malvaceae, juntamente com sua diversificação de hábitos e migração para áreas de vegetação aberta. Como um caráter derivado, a autogamia tornou-se grandemente preponderante, sendo uma das razões para o sucesso de muitas Malvaceae herbáceas como ervas daninhas pantropicais. Porém STEBBINS (1965) refere-se à Sida hederacea (Dougl.) K. Schum. como uma espécie auto-incompatível.

Algumas espécies de Sida são muito visitadas por abelhas, que coletam néctar e/ou pólen em suas flores (GIORGINI \& GUSMAN 1972; LAROCA 1970; CAMARGo \& MazuCATO 1984; Cure et al. 1992, 1993; Silveira et al. 1993). Em um estudo na região nordeste do Rio Grande do Sul, de um total de 292 espécies de abelhas coletadas, cerca de $16 \%$ o foram em flores de S. rhombifolia L. (S.) (ALVES-DOS-SANTOS 1999a). É possível, portanto, que a polinização cruzada tenha alguma importância em seu sistema reprodutivo.

Plantas do gênero Sida (UGBOROGHO 1980) e M. coromandelianum (E.F. Morato \& L.A. de O. Campos, observação pessoal) apresentam fenômeno de sincronização intraespecífica, bem como diferenças inter-específicas com relação ao horário de antese. Isso pode ter conseqüências sobre o horário em que as abelhas exploram os recursos florais oferecidos por essas plantas.

Foram objetivos desse trabalho: 1) estudar os padrões de antese diária das espécies de Sida e Malvastrum; 2) verificar os tipos de recursos florais oferecidos às abelhas; 3 ) investigar os padrões temporais de visitas das espécies de abelhas nas flores e as espécies de plantas visitadas; 4) investigar o comportamento das abelhas nas flores.

\section{MATERIAL E MÉTODOS}

A coleta de dados foi realizada entre os meses de fevereiro e agosto de 1987 no campus da Universidade Federal de Viçosa (UFV), Viçosa, Minas Gerais, Brasil.

Viçosa localiza-se a $20^{\circ} 46$ 'S e $42^{\circ} 54^{\prime} \mathrm{W}$ e a uma altitude de $657,8 \mathrm{~m}$, na Zona da Mata. De acordo com a classificação de Köppen, possui um clima do tipo tropical de altitude com verões frescos e chuvosos (Cwb) (VALVERDE 1958). A temperatura média anual é de $18,8^{\circ} \mathrm{C}$ e a precipitação média anual é de $1391,2 \mathrm{~mm}$. Apesar da intensa devastação a que foi submetida a Zona da Mata (VALVERDE 1958), a região de Viçosa ainda apresenta alguns remanescentes de Mata Atlântica semi-decídua (GOLFARI 1975).

Durante o período do estudo a temperatura média mensal variou entre 16,5 (julho) e $22,6^{\circ} \mathrm{C}$ (fevereiro). A precipitação média diária variou entre 0,4 (agosto) e 7,7 mm (março) e a umidade relativa média do ar entre 72 (agosto) e $87 \%$ (junho).

Plantas dos gêneros Sida e Malvastrum foram herborizadas e enviadas à Fundação Zoobotânica do Rio Grande do Sul e identificadas pela Dra. Olinda Leite Bueno. A identificação revelou a existência de sete espécies de Sida e uma de Malvastrum, a saber: Sida carpinifolia L., S. cordifolia L., S. glaziovii Schum., 
S. linifolia Cav., S. lonchitis St. Hil. \& Naud., S. tuberculata R. E. Fries, S. urens L. e Malvastrum coromandelianum (L.) Garcke. Os exemplares identificados encontram-se no Herbário do Departamento de Biologia Vegetal da UFV (VIC).

As populações de $S$. tuberculata e $M$. coromandelianum, observadas em Viçosa, mostraram-se polimórficas. Embora não tenha sido possível determinar a causa dessa variação, as formas foram designadas I e II. A forma designada $S$. tuberculata I apresenta flores com corola amarelada, porte menor, folhas sem coloração avermelhada e antese com início às 7:30 horas. A forma designada $S$. tuberculata II possui flores com forte anel vermelho no fundo da corola, folhas com nervuras avermelhadas, número menor de flores e antese com início às 8:30 horas. Em relação à forma I de $M$. coromandelianum, a forma II possui maior porte, maior número de flores, flores com maior diâmetro da corola e pico de flores abertas ocorrendo cerca de 1 hora mais tarde.

Foi escolhida uma área de estudo (AE) no campus-UFV, onde plantas pertencentes aos gêneros Sida e Malvastrum ocorriam. Essa área possuia superfície aproximada de $1670 \mathrm{~m}^{2}$. Além das espécies de Sida e Malvastrum, existiam também nessa área, plantas floridas das famílias Asteraceae, Verbenaceae, Tiliaceae, Lythraceae, Polygalaceae, Leguminosae, Solanaceae e Sterculiaceae. Nesse local procedeu-se, principalmente, a observações de visitas de abelhas nas flores de Sida e Malvastrum e registros dos horários de antese das plantas.

As abelhas usadas para a identificação e formação de uma coleção de referência foram coletadas em outras áreas do campus da UFV nas flores das mesmas espécies de Sida e Malvastrum. As mesmas foram identificadas pelo Pe. Jesus Santiago Moure (Universidade Federal do Paraná) e encontram-se depositadas no Museu de Entomologia do Departamento de Biologia Animal da UFV.

Foram feitas observações sobre o horário de abertura e fechamento das flores das espécies existentes na AE. Cada uma das espécies foi observada em um determinado dia. As datas e as plantas a serem observadas foram determinadas ao acaso. Um dia anterior a essas observações, plantas floridas foram marcadas com etiquetas numeradas e a cada planta foi atribuído um número. Foram observadas no máximo 30 plantas por espécie. No dia seguinte ao da marcação, procedeu-se a uma contagem do número de flores abertas em cada planta, entre intervalos de 30 minutos. Considerou-se como aberta aquela flor cujo fundo da corola estava completamente visível. Concomitantemente, foram marcados cerca de 308 botões florais, distribuídos entre as espécies de plantas estudadas, antes da antese, a fim de se verificar se, no dia seguinte, aquelas mesmas flores poderiam abrir novamente. Essa marcação foi feita utilizando etiquetas auto-adesivas de $2,5 \mathrm{~cm} \times 2 \mathrm{~mm}$, as quais foram colocadas no pedúnculo dos botões.

Uma vez por mês, entre abril e julho (20/04, 12/05, 07/06 e 12/07) o número de flores de cada espécie de planta foi contado na AE. As flores foram contadas com auxílio de contadores manuais, modelo "Hope". Essas contagens visaram estimar a variação na quantidade de flores ao longo do meses.

Foram observadas as visitas das abelhas nas flores durante 78 dias em 165 plantas distribuídas entre as espécies. O número de plantas floridas de algumas espécies diminuiu muito com o passar dos meses (notadamente, a partir de junho), 
razão pela qual o número de observações nelas realizado foi pequeno. O número de dias de observações das espécies de plantas variou entre 3 (S. cordifolia) e 12 (S. lonchitis).

Em cada dia de observação, foram escolhidas plantas que estavam próximas entre si. Essas plantas foram observadas enquanto nelas houvesse flores abertas. Considerou-se como visita a presença de abelhas nas flores e não sua presença na planta. Anotou-se a espécie da abelha, o sexo quando possível, o tipo de visita (i.e. se a abelha estava coletando néctar e/ou pólen), o horário e algum outro tipo de comportamento. Quando se constatou a presença da abelha na flor, mas sem executar coleta de pólen e/ou néctar e cópula, considerou-se essa visita como ocasional. Quando a abelha coletou pólen e néctar na mesma flor, atribuiu-se um escore para visita de pólen e outro para visita de néctar. Como a identificação das espécies de abelhas nas flores era difícil, as espécies que eram confundidas foram reunidas em grupos de morfo-espécies.

Como optou-se em não coletar abelhas na área de observações, as identificações de C. anomalus Moure \& Oliveira, 1962 e M. cnecomala (Moure, 1944) nas flores foram feitas por comparação com os insetos coletados em outras áreas. Estas abelhas são facilmente identificadas e não são confundidas com outras espécies de visitantes.

A amplitude (diversidade) de horário de flores abertas e de horário de visitas para as espécies de plantas foi calculada através do índice de Simpson (MACARTHUR 1972), o qual varia no intervalo de 1 (menor amplitude) e n (maior amplitude), onde n é igual ao número total de classes de horário. Cada classe compreendeu um intervalo de 30 minutos.

Foram realizadas análises de correlação não-paramétrica $\left(\mathrm{r}_{\mathrm{S}}\right)$ (SIEGEL \& CASTELLAN 1988) entre os valores de amplitude de horário de flores abertas e de horário de visitas; quantidade de flores, ao longo dos meses, e as variáveis climáticas precipitação diária média, temperatura diária média e umidade relativa diária média e entre as porcentagens de visitas para coleta de néctar e pólen realizadas pelas espécies de abelhas.

A proporção sexual de abelhas coletadas nas flores foi testada por um teste de $X^{2}$ para amostras independentes (SIEGEL \& CASTELLAN 1988).

Para as espécies de abelhas também foram calculados valores de amplitude (diversidade) em relação ao horário de visitas e às espécies de plantas visitadas, mediante o índice citado acima.

Foi calculado um valor de sobreposição (similaridade), entre cada espécie de planta, em relação ao horário de visitas de abelhas nas suas flores, mediante índice proposto por PIANKA (1973). Esse índice varia no intervalo compreendido entre 0 (nenhuma sobreposição) e 1 (sobreposição máxima). As espécies foram agrupadas, de acordo com esses valores, em um dendrograma, pelo método UPGMA (group mean unweighted pair-grouping method) (LUDWIG \& REYNOLDS 1988). Foram também calculados valores de sobreposição (similaridade) entre as espécies de abelhas, em relação ao horário de suas visitas às flores e às espécies de plantas visitadas. 


\section{RESULTADOS}

\section{Padrões de floração}

As flores das espécies de Sida e Malvastrum estudadas abrem uma única vez e permanecem abertas por poucas horas. Dos 308 botões marcados, momentos antes da antese, nenhum abriu novamente no dia seguinte.

Observou-se uma sincronia entre indivíduos de uma mesma espécie, em relação ao horário da antese. Esse fenômeno repetiu-se nos dias seguintes. Observou-se também uma diferença entre as espécies em relação ao horário de antese (Fig. 1). O horário em que ocorreu pico de floração foi característico para cada espécie. Houve espécies que apresentaram o pico pela manhã, outras pelo meio do dia e outras no período da tarde. Houve pequena sobreposição, em relação ao horário de floração, entre as espécies com pico no período da manhã e aquelas com pico no período da tarde.

Observações esporádicas feitas em dias frios nos meses de maio e junho mostraram que alguns indivíduos de S. tuberculata I e S. linifolia não apresentaram floração.

Houve uma acentuada diminuição do número de flores produzidas na $\mathrm{AE}$, ao longo dos meses (Fig. 2) com uma redução de $93,7 \%$, entre abril e junho. Foram encontradas correlações positivas entre a variação do número de flores, variação da precipitação média diária $\left(\mathrm{r}_{\mathrm{s}}=0,95 ; \mathrm{p}<0,05\right)$ e variação da temperatura média diária $\left(r_{\mathrm{S}}=0,95 ; \mathrm{p}<0,05\right)$, ao longo dos meses. Contudo, não houve correlação entre a variação do número de flores e a variação da umidade relativa $\left(\mathrm{r}_{\mathrm{s}}=-0,11 ; \mathrm{p}>0,05\right)$.

\section{Abelhas visitantes}

Foram observadas cerca de 1405 visitas de abelhas nas flores de Sida e Malvastrum. A maioria das visitas foi realizada por Melissoptila cnecomala (Apidae, Eucerini) (47,3\%) e por Cephalurgus anomalus (Andrenidae, Panurginae) $(23,1 \%)$. Por isso, somente essas espécies serão tratadas nesse trabalho. Tanto fêmeas como machos da última espécie visitaram as flores. O restante das visitas foi realizado por espécies de Halictidae, Andrenidae, Apidae e Colletidae.

Em outras áreas do campus da UFV foram coletadas cerca de 567 abelhas nas flores de Sida e Malvastrum coromandelianum. Em S. carpinifolia e $S$. urens a porcentagem de espécimens coletada foi muito pequena $(0,9$ e $0,4 \%$, respectivamente). Em S. glaziovii, S. tuberculata I e S. lonchitis foram coletadas as maiores porcentagens $(28,2 ; 22,9$ e $17,1 \%$, respectivamente).

Cerca de $52,0 \%$ do número total coletado correspondeu a C. anomalus ( 186 fêmeas: 109 machos). De modo geral, o número de fêmeas foi, significativamente, maior que o de machos $\left(X^{2}=20,1 ; \mathrm{p}<0,001\right)$. Esta espécie foi coletada nas flores de S. glaziovii (16,9\%; 64 fêmeas: 32 machos), S. tuberculata I (12,5\%; 50 fêmeas: 21 machos), S. lonchitis (10,9\%; 29 fêmeas: 33 machos), S. cordifolia (3,9\%; 18 fêmeas: 4 machos), S. linifolia (3,4\%; 9 fêmeas: 10 machos), S. tuberculata II (2,8\%; 12 fêmeas: 4 machos), S. carpinifolia ( $0,7 \% ; 4$ machos), M. coromandelianum I ( $0,5 \%$; 2 fêmeas: 1 macho) e $M$. coromandelianum II ( $0,4 \% ; 2$ fêmeas).

M. cnecomala correspondeu a apenas $4,5 \%$ do total de espécimens ( 22 fềmeas: 3 machos). O número de fềmeas foi, significativamente, maior que o de 

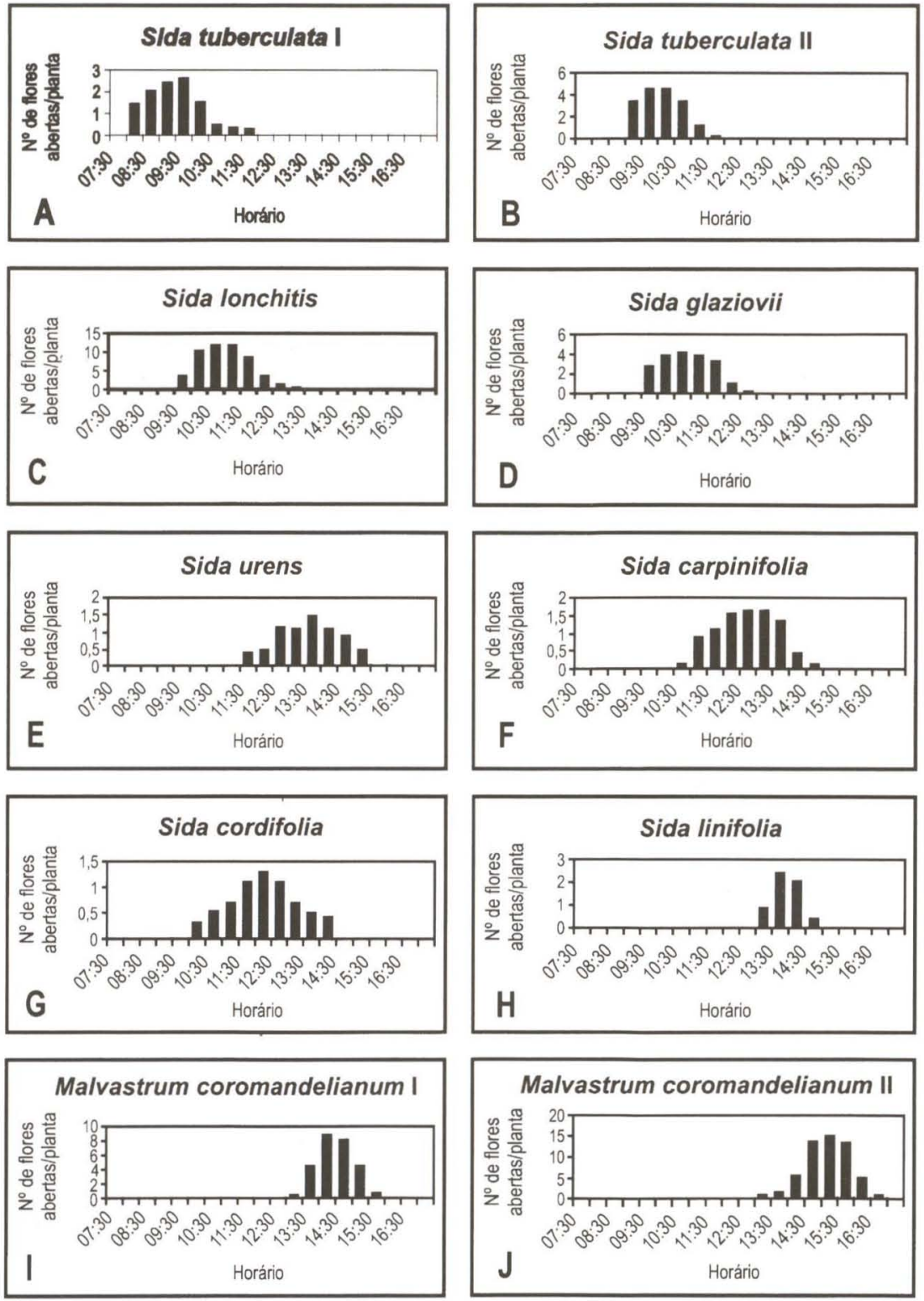

Fig. 1. Horário de antese das espécies de Sida e Malvastrum em 1987. As datas das determinações e o número de plantas $(n)$ de cada amostra são os seguintes: $S$. tuberculata I (07/III, $n=24)$; S. tuberculata II $(28 / I I I, n=20)$; S. Ionchitis $(04 / I I I, n=25)$; S. glaziovii $(15 / I I I$, $n=30) ; S$. urens (11/IV $n=20) ; S$. carpinifolia (22/III, $n=20)$; S. cordifolia $(16 / \mathrm{IV}, n=10)$; $S$. linifolia (08/III, $n=30) ; M$. coromandelianum I (07/III, $n=20) ; M$. coromandelianum II ( $16 \mathrm{~N}$, $n=9)$. O número de flores abertas foi dividido pelo número de plantas observadas em cada amostra. 
machos $\left(X^{2}=14,4 ; p<0,001\right)$. Esta espécie foi coletada nas flores de $M$. coromandelianum II (5 fềmeas), M. coromandelianum I (4 fềmeas: 1 macho), S. lonchitis (6 fềmeas), S. linifolia (3 fêmeas), S. tuberculata I (3 fềmeas), S. tuberculata II (1 macho), S. cordifolia (1 macho) e S. urens (1 fềmea).

Os demais espécimens coletados pertencem às famílias Halictidae $(27,7 \%)$, Apidae (10,3\%), Andrenidae (3,9\%), Colletidae $(1,6 \%)$ e Megachilidae $(0,2 \%)$.

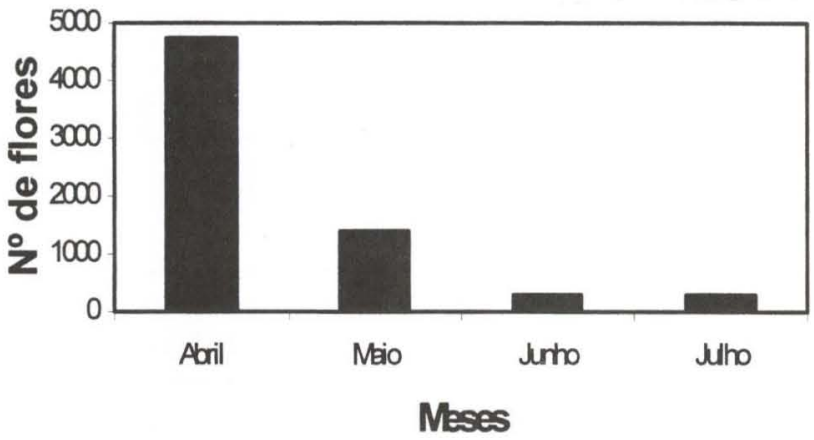

Fig. 2. Número de flores de Sida spp. e Malvastrum coromandelianum em amostragens realizadas nos meses de abril, maio, junho e julho.

\section{Recursos florais oferecidos e quantidade de visitas recebidas pelas plantas}

As flores de Sida e Malvastrum oferecem néctar e pólen às abelhas. Cerca de $35,7 \%$ das visitas de $C$. anomalus resultaram em coleta de néctar; $25,9 \%$ em coleta de pólen; 19,2\% foram visitas ocasionais (não resultaram em coleta de pólen ou néctar) e em 19,2\%, o macho foi observado nas flores esperando por uma fêmea para copular.

Cerca de $56,4 \%$ das visitas realizadas por $M$. cnecomala resultaram em coleta de néctar; $34,1 \%$ em coleta de pólen e 9,5\% foram visitas ocasionais.

A quantidade de visitas recebidas variou entre as espécies de plantas. Os números de visitas que resultaram em coleta de néctar e pólen foram maiores em M. coromandelianum II e Sida lonchitis.

\section{Padrões temporais de visitas e espécies de plantas visitadas}

As espécies apresentaram diferentes horários de antese e também foram visitadas pelas duas espécies de abelhas em horários diferentes (Fig. 3). Não se observou uma faixa contínua no horário de visitas em $S$. carpinifolia e $S$. linifolia.

A tabela I mostra valores de amplitude de horário de flores abertas e horário de visitas para as espécies de plantas. Das espécies que possuem antese no período da manhã, $S$. tuberculata I apresentou maior amplitude de horário de flores abertas e das com antese no período da tarde, M. coromandelianum II apresentou a maior.

$S$. cordifolia e $S$. carpinifolia apresentaram maior amplitude de horário de flores abertas. Contudo, os maiores valores de amplitude de horário de visitas foram encontrados em $S$. urens e S. tuberculata II. S. linifolia foi a espécie que apresentou as menores amplitudes, tanto de horário de flores abertas como de horário de visitas. 


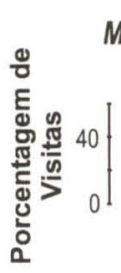

M. coromandelianum I
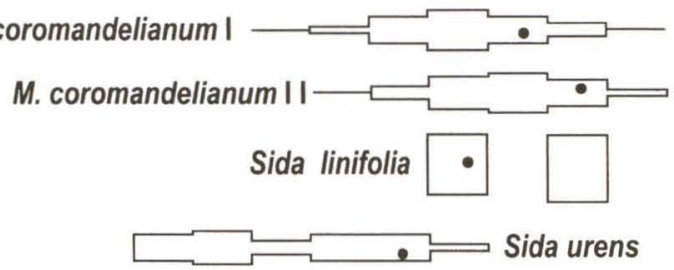

Sida carpinifolia
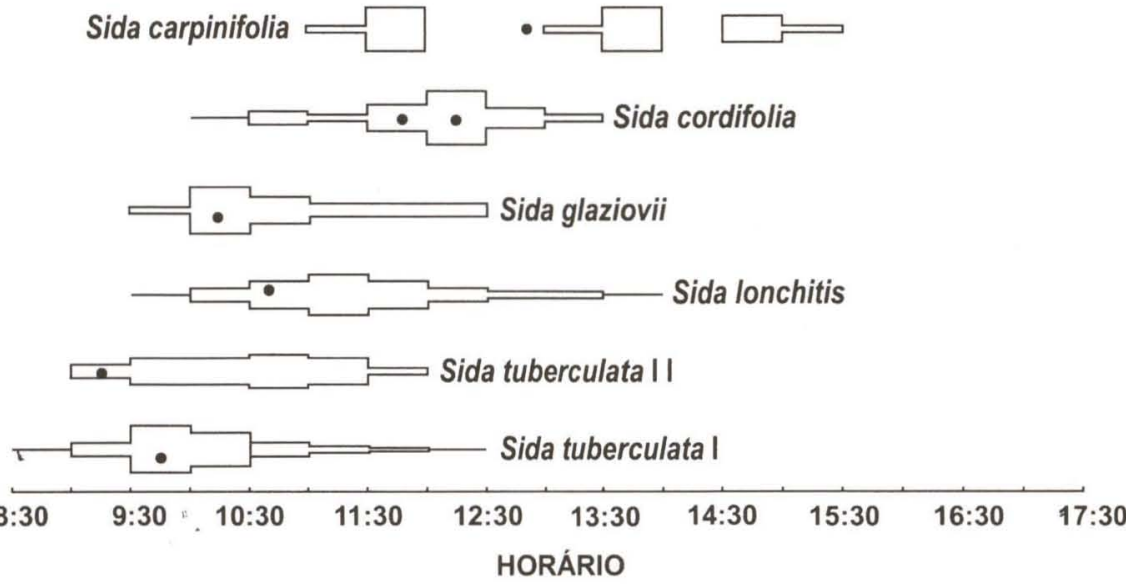

Fig. 3. Porcentagem de visitas realizadas por $C$. anomalus e $M$. cnecomala nas espécies de Sida e Malvastrum coromandelianum em diferentes horários. Os círculos escuros indicam os horários de picos de floração.

Tabela I. Valores de amplitude (diversidade) de horário de flores abertas e de visitas para as espécies de plantas.

\begin{tabular}{lcc}
\hline \multicolumn{1}{c}{ Plantas } & $\begin{array}{c}\text { Amplitude de horário } \\
\text { de flores abertas }\end{array}$ & $\begin{array}{c}\text { Amplitude de horário } \\
\text { de visitas }\end{array}$ \\
\hline S. tuberculata I & 6,024 & 4,016 \\
S. tuberculata II & 4,464 & 5,319 \\
S. glaziovii & 5,473 & 4,505 \\
S. lonchitis & 5,319 & 4,808 \\
S. cordifolia & 7,407 & 3,968 \\
S. carpinifolia & 7,153 & 3,774 \\
S. urens & 6,410 & 5,464 \\
S. linifolia & 2,959 & 1,992 \\
M. coromandelianum I & 3,717 & 4,032 \\
M. coromandelianum II & 4,292 & 3,676 \\
\hline
\end{tabular}

Embora o horário de visitas seja dependente do horário em que existam flores abertas, não houve uma correlação significativa entre os valores de amplitude de horário de flores abertas e de horário de visitas $\left(\mathrm{r}_{\mathrm{s}}=0,20 ; \mathrm{p}>0,05\right)$. 
Os horários de maiores freqüências de visitas coincidiram pouco. Plantas com maior número de flores abertas no período da manhã apresentaram maior sobreposição no horário de visitas entre si do que com plantas com maior número no período da tarde e vice-versa (Fig. 4; Tab. II).

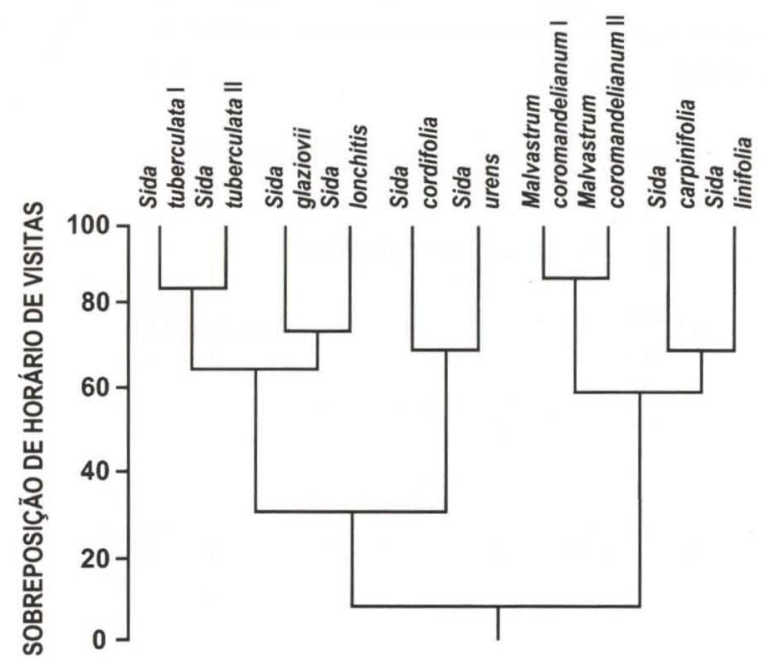

Fig. 4. Dendrograma de sobreposição de horário de visitas de $C$. anomalus e $M$. cnecomala entre espécies de Sida e Malvastrum coromandelianum. Os valores de sobreposição (índice de Pianka) foram multiplicados por 100 .

Tabela II. Matriz de sobreposição (similaridade), entre as espécies de plantas, em relação ao horário de visitas realizadas pelas espécies de abelhas.

\begin{tabular}{lccccccccc}
\hline & $\begin{array}{c}\text { Sida } \\
\text { tuberculatata } \\
\text { I }\end{array}$ & $\begin{array}{c}\text { Suberculata } \\
\text { II }\end{array}$ & $\begin{array}{c}\text { Sida } \\
\text { glaziovii }\end{array}$ & $\begin{array}{c}\text { Sida } \\
\text { lonchitis }\end{array}$ & $\begin{array}{c}\text { Sida } \\
\text { cordifolia }\end{array}$ & $\begin{array}{c}\text { Sida } \\
\text { carpinifolia }\end{array}$ & $\begin{array}{c}\text { Sida } \\
\text { urens }\end{array}$ & $\begin{array}{c}\text { Sida } \\
\text { linifolia }\end{array}$ & $\begin{array}{c}\text { Malvastrum } \\
\text { coromandelianum } \\
\text { I }\end{array}$ \\
\hline M. coromandelianum II & 0,000 & 0,000 & 0,000 & 0,013 & 0,023 & 0,574 & 0,161 & 0,733 & 0,886 \\
M. coromandelianum I & 0,000 & 0,000 & 0,003 & 0,044 & 0,120 & 0,542 & 0,385 & 0,570 & - \\
S. linifolia & 0,000 & 0,000 & 0,000 & 0,005 & 0,000 & 0,705 & 0,100 & - & - \\
S. urens & 0,089 & 0,237 & 0,308 & 0,641 & 0,703 & 0,513 & - & - & - \\
S. carpinifolia & 0,043 & 0,108 & 0,177 & 0,362 & 0,259 & - & - & - & - \\
S. cordifolia & 0,111 & 0,202 & 0,453 & 0,498 & - & - & - & - & - \\
S. lonchitis & 0,395 & 0,728 & 0,759 & - & - & - & - & - & - \\
S. glaziovii & 0,693 & 0,822 & - & - & - & - & - & - & - \\
S. tuberculata II & 0,846 & - & - & - & - & - & - & - & - \\
\hline
\end{tabular}

Foram mais freqüentes, em relação ao horário de visitas entre as espécies de plantas, valores de sobreposição compreendidos entre 0 e 0,100 (Fig. 5). $\mathrm{O}$ valor médio de sobreposição foi igual a 0,307 . 


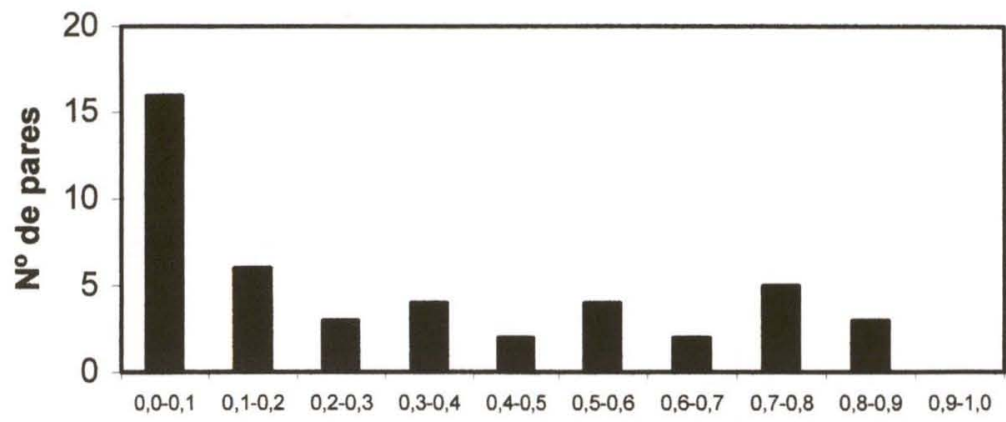

Valores de sobreposição

Fig. 5. Distribuição de freqüência de valores de sobreposição em horário de visitas entre as espécies de plantas. O valor médio de sobreposição foi igual a 0,307.

O maior valor calculado de sobreposição $(0,886)$ ocorreu entre as formas I e II de M. coromandelianum. Não houve sobreposição entre $S$. tuberculata I e $M$. coromandelianum I, $M$. coromandelianum II e $S$. linifolia; entre $S$. tuberculata II e essas mesmas espécies; entre $S$. glaziovii e $M$. coromandelianum II e S. linifolia e entre $S$. cordifolia e $S$. linifolia.

As espécies de plantas não foram igualmente visitadas para coleta de pólen e néctar pelas espécies de abelhas (Fig. 6). Tanto para coleta de pólen como para coleta de néctar, S. tuberculata II, S. lonchitis, S. glaziovii e S. carpinifolia foram mais visitadas por $C$. anomalus, tanto por fêmeas como por machos. $S$. tuberculata I, S. cordifolia, S. linifolia, S. urens, M. coromandelianum I e M. coromandelianum II foram visitadas, principalmente, por M. cnecomala. Não se observou machos desta espécie visitando as flores. Assim, plantas com antese no período da manhã foram visitadas, principalmente, por $C$. anomalus e plantas com antese no período da tarde foram mais visitadas por M. cnecomala.

As espécies de plantas mais visitadas por $C$. anomalus para coleta de néctar também o foram para pólen $\left(\mathrm{r}_{\mathrm{s}}=0,76 ; \mathrm{p}<0,05\right)$, o mesmo ocorrendo para $M$. checomala $\left(\mathrm{r}_{\mathrm{s}}=0,98 ; \mathrm{p}<0,05\right)$.

A sobreposição, em relação ao horário de visitas entre $C$. anomalus e $M$. cnecomala foi de apenas 0,239 e a sobreposição, em relação às espécies de plantas visitadas, foi de apenas 0,090 .

Em relação ao horário de visitas, $M$. cnecomala apresentou um valor de amplitude $(5,817)$ ligeiramente superior ao de $C$. anomalus $(5,580)$. C. anomalus apresentou maiores amplitudes em relação a $M$. cnecomala, tanto em espécies de plantas visitadas para coleta de néctar (3,315 e 2,606, respectivamente) como para coleta de pólen (3,827 e 3,076, respectivamente).

M. cnecomala realizou, significativamente, mais visitas para coleta de néctar em S. tuberculata I do em $S$. tuberculata II $\left(X^{2}=33,8 ; \mathrm{p}<0,001\right)$, o mesmo ocorrendo em relação às visitas para coleta de pólen $\left(X^{2}=11,5 ; \mathrm{p}<0,001\right) . M$. cnecomala também realizou, significativamente, um maior número de visitas em M. coromandelianum II do que em $M$. coromandelianum I, tanto para coleta de $\operatorname{néctar}\left(X^{2}=126,8 ; p<0,0001\right)$, como de pólen $\left(X^{2}=63,5 ; p<0,0001\right)$. 
A) C. anomalus

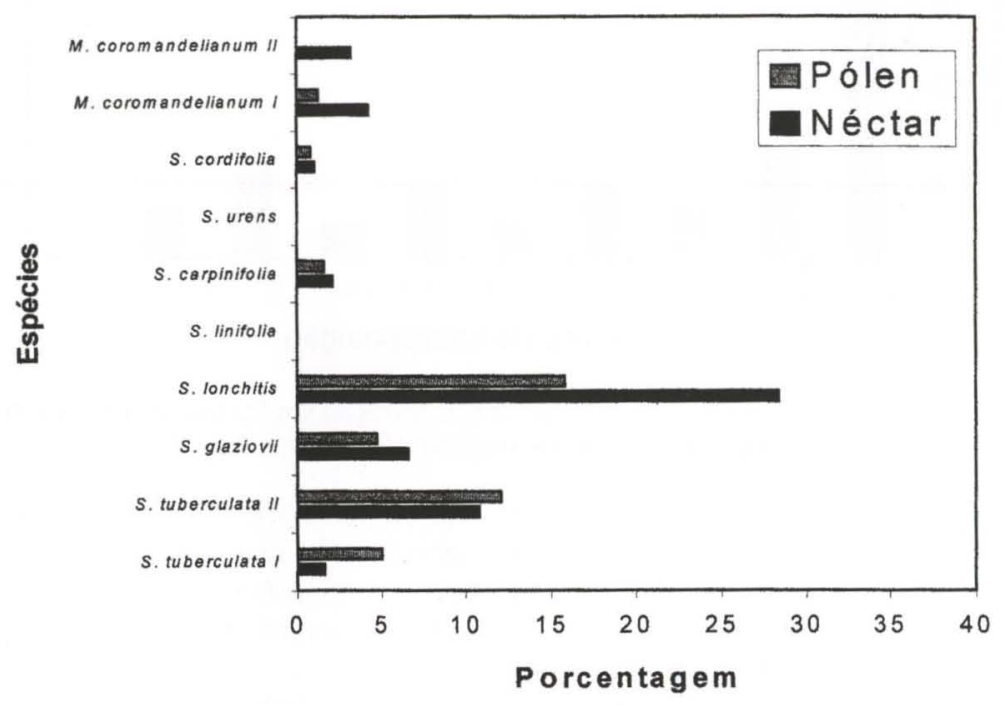

B) M. cnecomala

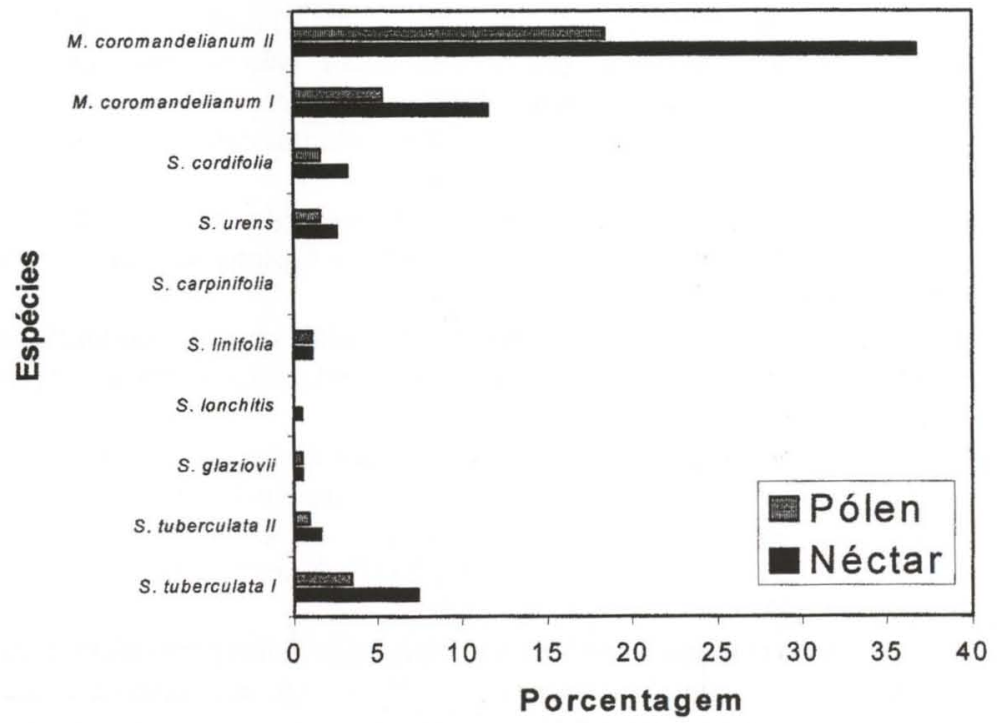

Fig. 6. Visitas realizadas por C. anomalus (A) e M. cnecomala (B) (porcentagenıs sobre 264 e 906 visitas, respectivamente) para coleta de néctar e pólen em espécies de Sida e Malvastrum coromandelianum. 
C. anomalus realizou, significativamente, maior número de visitas em $S$. tuberculata II do que em $S$. tuberculata $\mathrm{I}$, tanto para coleta de néctar $\left(X^{2}=12,7 ; \mathrm{p}\right.$ $<0,001)$ como para coleta de pólen $\left(X^{2}=8,0 ; p<0,005\right)$. Contudo, entre $M$. coromandelianum I e II não houve diferenças significativas para coleta de néctar $\left(X^{2}=0,05 ; p>0,75\right)$. Em relação às visitas para coleta de pólen, foram realizadas apenas $4 \mathrm{em} \mathrm{M}$. coromandelianum I e nenhuma em M. coromandelianum II.

\section{Comportamento das abelhas nas flores}

Melissoptila cnecomala visitou as flores de Sida e Malvastrum principalmente após as 12:30 horas (Fig. 7). O pico de visitas para coleta de néctar ocorreu entre 14:00 e 14:30 horas e o pico de visitas para coleta de pólen entre 13:30 e 14:00 horas. Apenas as fêmeas foram observadas visitando as flores, embora três machos dessa espécie tenham sido coletados nessas flores em outros locais do campus da UFV.

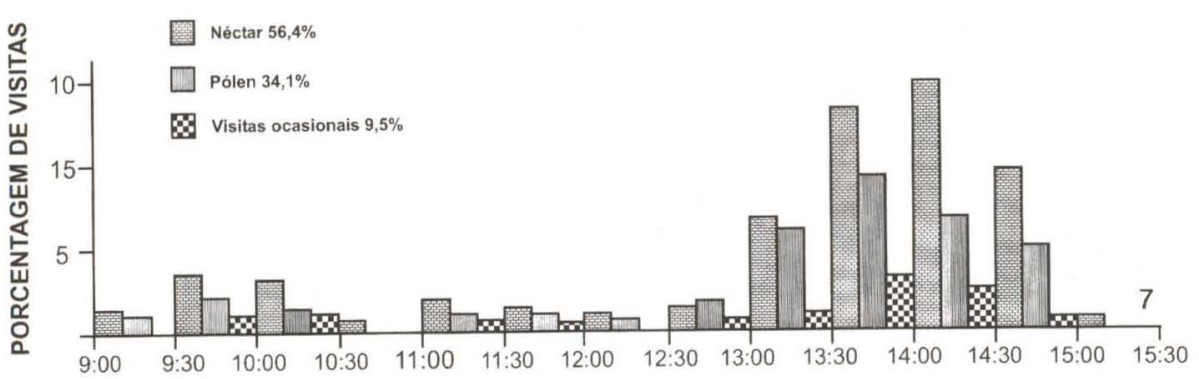

HORARIO

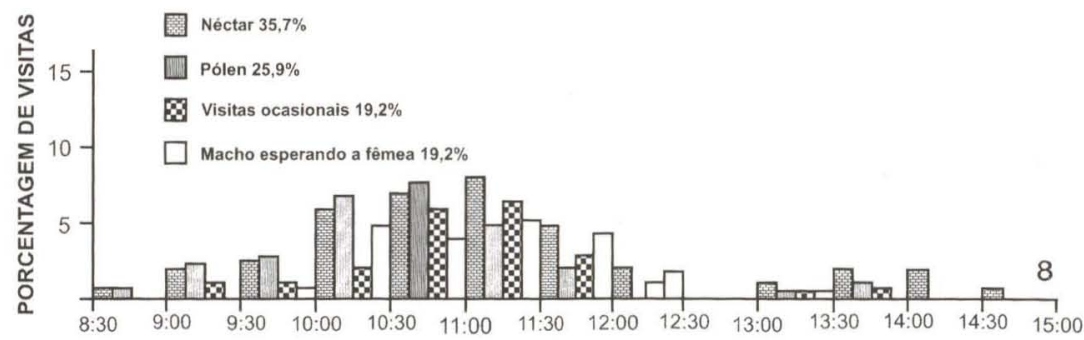

HORÁRIO

Figs 7-8. Diferentes tipos de visitas realizadas, em diferentes horários, nas espécies de Sida e Malvastrum coromandelianum. (7) M. cnecomala, porcentagens calculadas sobre 1002 visitas; (8) C. anomalus, porcentagens calculadas sobre 429 visitas.

Tanto fêmeas como machos de C. anomalus visitaram as flores. A maior parte das visitas dessa espécie foram realizadas antes das 12:30 horas (Fig. 8). O pico de visitas para coleta de néctar ocorreu entre 11:00 e 11:30 horas, período que coincidiu com a maior atividade de machos esperando as fêmeas nas flores. O pico de visitas para coleta de pólen ocorreu entre 10:30 e 11:00 horas. 
Entre 12:00 e 13:00 horas, quase todas as plantas que apresentaram pico de flores abertas pela manhã, encontravam-se com as flores, total ou parcialmente, fechadas. Nesse horário foram observadas, várias vezes, fêmeas de C. anomalus $\mathrm{e}$ M. cnecomala, forçando a abertura das flores e exibindo comportamento de coleta.

As flores de Sida também servem como sítio de cópula para C. anomalus. Não se observou cópulas de $M$. cnecomala nas flores. A maioria das cópulas observadas ocorreu em flores de S. lonchitis, entre 10:30 e 11:30 horas. As fềmeas começaram a visitar as flores ligeiramente mais cedo que os machos. O maior número de visitas de fêmeas ocorreu entre 10:30 e 11:00 horas, ao passo que o de machos ocorreu entre 11:00 e 11:30 horas.

O macho de C. anomalus, ao visitar uma flor, posiciona-se em volta do tubo estaminal e aguarda a chegada da fềmea (Fig. 9a). Antes, ele pode ou não alimentar-se de néctar naquela flor. Esse comportamento foi mais freqüente entre 10:00 e 12:00 horas (Fig. 8). Quando uma fêmea pousa na flor, onde já se encontra um macho, e começa a coletar néctar e/ou pólen, ele tenta copular com ela (Fig. 9b). A fêmea pode voar, mas mesmo assim o macho a segue e continua tentando a cópula durante o vôo. Quando a fêmea permanece na flor, durante os movimentos de cópula, grãos de pólen podem aderir no corpo tanto seu como do macho. Quando o macho pousa numa flor onde já se encontra uma fềmea, ele também tenta copular com ela. Algumas vezes, observaram-se dois machos lutando pela posse de uma fêmea e também machos lutando pela posse de flores. Entretanto, em uma ocasião, observou-se um macho de outra espécie de Panurginae alimentando-se de néctar na mesma flor onde encontrava-se um macho de C. anomalus esperando pela fêmea. Contudo, nessa situação, não se observou comportamento agressivo entre ambos.

\section{DISCUSSÃO}

A época de floração das espécies de Sida estudadas em Viçosa foi parecida com a das espécies desse gênero estudadas em Ribeirão Preto, São Paulo, por CAMARGO \& MAZUCATO (1984).

Em uma comunidade os padrões temporais de floração podem ter conseqüências ecológicas sobre as espécies de plantas e seus visitantes florais (HEITHAUS 1974; LINSLEY 1978; RATHCKE 1983; ARMBRUSTER \& HERZIG 1984; CAMPBELL \& MOTTEN 1985; MURRAY et al. 1987). A probabilidade de ocorrência de polinizadores em uma espécie de planta em um local pode ser inversamente relacionada à probabilidade de existência de outras espécies em floração naquela local (HEINRICH \& RAVEN 1972). Nesse aspecto, uma separação temporal na floração é seletivamente vantajosa para as espécies de plantas.

As espécies de Sida e Malvastrum estudadas apresentaram picos de floração em diferentes horários e foram visitadas pelas abelhas nesses horários. Embora, na maioria das vezes, o horário de pico de visitas não tenha coincidido com o horário de pico de floração, as espécies receberam visitas em diferentes horários. Isso foi mais acentuado entre aquelas com pico de floração pela manhã e aquelas com pico pela tarde. A maioria das espécies apresentaram, entre si, valores de sobreposição de horário de visitas muito baixos (menores que 0,100 ). Entre algumas espécies não houve, inclusive, sobreposição. 

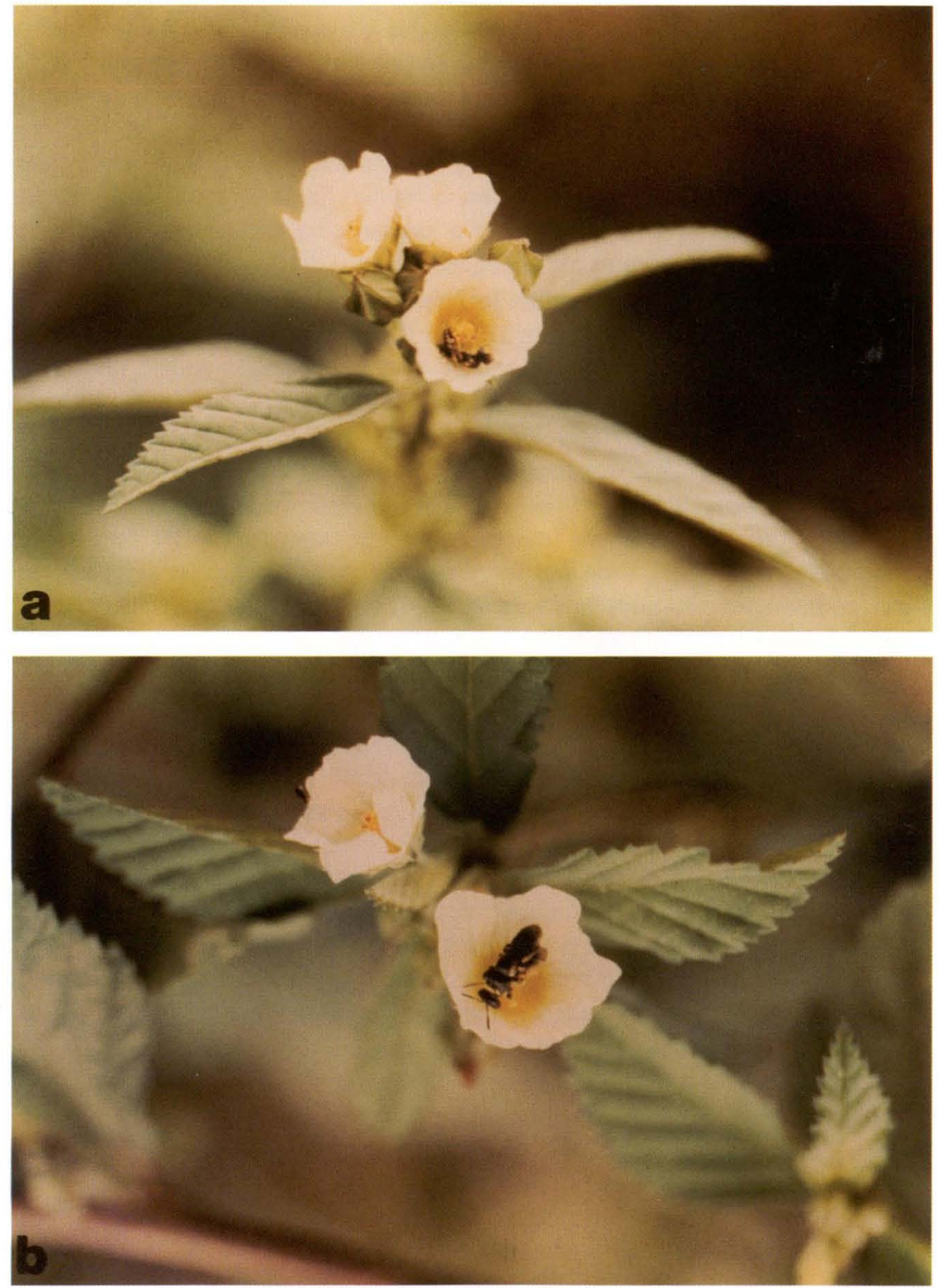

Fig. 9. Macho de $C$. anomalus pousado em uma flor de $S$. lonchitis, em volta do tubo estaminal, aguardando uma fêmea (a). Macho e fêmea em cópula em uma flor de $S$. lonchitis, Viçosa, Minas Gerais (b). 
As plantas apresentaram também sincronia intra-específica em relação à floração. Ambos os fenômenos repetiram-se quase todos os dias, durante o estudo. Observações esporádicas mostraram que, em outras áreas do campus da UFV e, também, em outros municípios do estado de Minas Gerais, o fenômeno ocorre de forma semelhante. Em áreas desmatadas da Amazônia Central, em região próxima de Manaus, AM, fenômeno semelhante foi também constatado (E.F. Morato, dados não publicados). Isso indica que, embora variáveis climáticas possam influenciar, a determinação do horário de antese e a sincronia na floração dessas espécies parecem ter um forte componente endógeno.

Nos dias em que a temperatura foi baixa, em relação às condições de Viçosa, algumas espécies não abriram as flores e nelas não se observou atividade de abelhas. Fatores físicos como baixas temperaturas, vento e insolação podem diminuir a atividade de vôo das abelhas (BURRIL \& DIETZ 1981), principalmente, das solitárias com pequena capacidade termorregulatória (EICKWORT \& GINSBERG 1980).

UGBOROGHO (1980) relatou a ocorrência de diferenças no horário de floração entre três variedades de $S$. rhombifolia L. na Nigéria e uma sincronia entre as plantas de uma mesma variedade em intervalos de aproximadamente 24 horas. Essa periodicidade seria governada por fatores endógenos das plantas. Segundo esse autor, contudo, temperaturas baixas retardam o horário de antese e fechamento das flores e o excesso de iluminação, o horário de antese.

EwUSIE (1972) constatou em Gana que as flores de S. stipulata Chapm. podem abrir mais de uma vez. Tal não foi encontrado por UGBOROGHO (1980) em S. rhombifolia. Neste estudo as flores de Sida e Malvastrum abriram uma única vez e fecharam dentro de poucas horas. Tal fato também foi observada na Amazônica Central por E.F. Morato (dados não-publicados). A viabilidade dos grãos de pólen de uma planta decresce com o passar do tempo sob ação de vários fatores (STANLEY \& LINSKENS 1974; THOMSON \& THOMSON 1992). Quando a diminuição da viabilidade é rápida, uma liberação freqüente de pequenas quantidades de grãos pode ser vantajosa (STEPHENSON \& BERTIN 1983). A viabilidade reduzida dos grãos de pólen poderia ser um fator responsável pela pequena longevidade das flores de Sida e Malvastrum estudadas. Consequentemente, as abelhas sempre forrageiam em flores novas que sofreram antese há pouco tempo.

Uma vez que os sistemas de reprodução das plantas de Sida e Malvastrum não foram estudados neste trabalho, é difícil inferir sobre o significado evolutivo da periodicidade e das diferenças inter-específicas observadas no horário de floração. A auto-incompatibilidade, contudo, não é uma característica esperada em plantas ruderais, pelo fato de serem r-estrategistas (MACARTHUR 1972; BAKER 1974; RoughGarden 1979; LOMNICKI 1988; RiCKLEFS 1990; COUSENS \& MORTIMER 1995). Freqüentemente, diferenças temporais de floração têm sido apontadas como resultantes da pressão de competição por polinizadores (HEINRICH \& RAVEN 1972; LACK 1982a,c; RATHCKE 1983; CAMPBELL 1985b). De qualquer forma, essas diferenças oferecem a certas espécies de plantas a oportunidade de serem exploradas em horários diferentes e por visitantes também diferentes, conforme observado neste trabalho. 
Diferenças em relação à horários de antese são propícias à evolução e manutenção de relações especializadas entre plantas e visitantes florais. Floração matinal, por exemplo, tem, freqüentemente, favorecido evolução de oligolecia nas abelhas (ESTES \& THORP 1975; LINSLEY 1978). Essas diferenças são também propícias à evolução de estratégias de forrageamento capazes de minimizarem a competição inter-específica entre os visitantes por recursos florais.

As diferenças, em relação ao horário de visitas e às espécies de plantas visitadas, entre $C$. anomalus e $M$. cnecomala sugerem a ocorrência de partição de recursos florais entre elas. Portanto, a competição pelo néctar e pólen dessas plantas, entre essas espécies de abelhas, deve ter sido pequena no período de estudo. $C$. anomalus visitou, principalmente, S. lonchitis enquanto $M$. cnecomala visitou, principalmente, M. coromandelianum. Possivelmente, por ser uma abelha com necessidades tróficas maiores, o forrageamento em plantas que produzem muitas flores como M. coromandelianum deve ser mais vantajoso. Esta espécie, inclusive, visitou diferencialmente as formas I e II de S. tuberculata e M. coromandelianum. Cephalurgus anomalus também visitou diferencialmente as formas I e II de $S$. tuberculata. Este fato reforça a separação, baseada em atributos vegetativos e nos horários de antese, realizada neste trabalho destas duas espécies em duas formas distintas. Variação intra-específica foi também relatada em populações de Petunia excellens R.E.Fr. (Solanaceae) em relação ao tamanho e forma das folhas e pétalas. Esta espécie é visitada pela abelha oligolética Callonychizm petuniae Cure \& Wittmann, 1990 (Panurginae) no Rio Grande do Sul (WitTMAnN et al. 1990).

Diferentemente do obtido neste trabalho, CAMARGO \& MAZUCATO (1984) coletaram em Ribeirão Preto, cerca de 345 indivíduos de C. anomalus, dos quais 320 o foram em flores de S. linifolia, espécie que recebeu apenas visitas ocasionais dessa abelha. De forma semelhante aos resultados de CAMARGO \& MAZUCATO (1984), não foi observada nenhuma visita de $C$. anomalus em $S$. urens. Esses autores referem-se a $C$. anomalus como uma espécie oligolética em relação às flores de Sida spp.

Segundo CAMARgo \& MAZUCATO (1984) além de S. linifolia, C. anomalus visitou ainda $S$. cordifolia e outras 8 espécies pertencentes às famílias Asteraceae, Cucurbitaceae, Labiatae e Onagraceae. Além de C. anomalus, S. linifolia e S. cordifolia foram visitadas por 35 e 15 outras espécies de abelhas, respectivamente.

Segundo Rozen (1989), em Cosmópolis, São Paulo, espécies de Sida constituem a principal fonte de alimento para C. anomalus. Segundo ele, a atividade externa dos adultos coincide com o período diário da floração dessas plantas. Essa atividade diminui muito após as 11:30 horas, o que coincide com os resultados do presente trabalho.

Em uma pastagem abandonada em Ponte Nova, Minas Gerais, Silveira et al. (1993) coletaram apenas um indivíduo de C. anomalus em Sida sp. Em uma pastagem abandonada na região de Viçosa, Minas Gerais, CURE et al. (1993) coletaram C. anomalus em flores de S. carpinifolia, S. cordifolia e em duas outras espécies não identificadas deste gênero.

No presente estudo, M. cnecomala visitou flores de Sida spp., com exceção de $S$. carpinifolia. Ao que tudo indica, Melissoptila é um visitante comum de Sida spp. CAMARGo \& MAZuCATO (1984) relataram visitas de Melissoptila sp. em Sida 
spp., principalmente, em S. cordifolia. LAROCA (1970) relatou visitas de M. thoracica Smith, 1854 em flores de S. carpinifolia. Sil VEIRA et al. (1993) coletaram M. cnecomala em flores de Sida spp. e CURE et al. (1993) em flores de S. cordifolia. Diferentemente do presente estudo, CURE et al. (1993) constataram poucas visitas de abelhas em S. tuberculata. ALVES-DOS-SANTOS (1999a) coletou M. cnecomala em S. rhombifolia L. (S.) e M. bonaerensis Holmberg, 1903 em S. micrantha St. Hil. e S. rhombifolia L. (S.).

Há uma grande variação entre as espécies de abelhas, em relação ao local que os machos procuram pelas fêmeas e as cópulas acontecem. Os machos procuram por fêmeas onde elas são mais numerosas (EICKWORT \& GINSBERG 1980; THORNHILL \& ALCOCK 1983). Em Andrena erythronii Robertson 1891 (Andrenidae: Andreninae), os machos procuram nos locais de emergência e copulam com fềmeas virgens. Em Nomadopsis spp. (Andrenidae: Panurginae), eles procuram nos locais onde elas constroem os ninhos (THORNHILL \& ALCOCK 1983).

Neste trabalho, foi constatado que $C$. anomalus copula, principalmente, nas flores de Sida lonchitis, no período da manhã. ROZEN (1989) não observou cópulas de C. anomalus nas flores de Sida spp. Contudo, concluiu que as mesmas devem ter início nas flores, pelo fato, de nelas ter sido observado um grande número de machos. Além disso, os mesmos não foram constatados nas áreas de nidificação.

Cópulas em flores são muito comuns entre abelhas (EICKWORT \& GINSBERG 1980; ThORNHill \& AlCOCK 1983; CuRE \& WitTMANN 1990; WitTMANn et al. 1990; Alves-DOS-SAnTos 1999b). Segundo Thornhill \& Alcock (1983), o comportamento de cópula nas flores parece ser mais freqüente em espécies de abelhas que apresentam baixas densidades de ninhos. Nessa situação, a sẹleção natural favoreceria machos que procuram por fềmeas nos locais de forrageamento. Essa estratégia deve ser vantajosa, sobretudo, se as fontes alimentares também não forem muito dispersas. Neste caso, o sucesso reprodutivo do macho dependerá de sua capacidade de escolher flores que são freqüentemente visitadas pelas fềmeas co-específicas (WITTMANN et al. 1990).

A presença simultânea de abelhas polinizadoras, de ambos os sexos, sobre uma mesma flor com resultante acasalamento, foi denominada como rendevouz pollination (FAEGRI \& VAN DER PIJL 1979). O comportamento de C. anomalus poderia ser definido como sendo desse tipo. Esse comportamento foi relatado também em Megandrena mentzeliae Zavortink, 1972 (Andrenidae: Andreninae) nas flores de Mentzelia tricuspis (Loasaceae) (ZAVORTINK 1972).

Segundo ZAVORTINK (1972), os machos de Megandrena mentzeliae copulam com fêmeas mortas há pouco tempo nas flores de Mentzelia tricuspis. Essas cópulas são muito semelhantes às cópulas normais. Contudo, o macho arrasta a fêmea para fora da flor. Parece, portanto, que em cópulas normais a fêmea resiste aos movimentos do macho e torna possível a cópula na flor. Em C. anomalus fenômeno semelhante deve ocorrer. Durante a cópula é muito comum a fêmea continuar coletando pólen ou néctar. A permanência do casal na flor deve aumentar a eficiência da polinização.

Em Megandrena mentzeliae enquanto o casal está na flor, outros machos tentam copular com a fêmea. Comportamento semelhante foi observado algumas vezes em C. anomalus. Em Megandrena mentzeliae não se observou machos alimentando-se 
de néctar nas flores de Mentzelia tricuspis. Quando uma flor está ocupada por uma fêmea, o macho que está patrulhando nas imediações voa em direção a ela. Se a abelha presente na flor for de outra espécie ou mesmo um macho da mesma espécie, ele não tenta a cópula e deixa a flor imediatamente (ZAVORTINK 1972).

O comportamento de cópula em flores também foi relatado para Callonychium petuniae (Panurginae) (WITTMANN et al. 1990) no sul do Brasil. Esta espécie é oligolética em relação à Petunia spp. (Solanaceae). O macho pode esperar pelas fêmeas co-especificas nas flores de Petunia spp. e apresenta um comportamento parecido com o descrito para os machos de C. anomalus neste trabalho. Ele alimenta-se de néctar nas flores enquanto aguarda uma fêmea e assim que ela pousa na flor, tenta copular. O macho também ataca outros machos co-específicos quando aproximam da mesma flor onde ele se encontra. As cópulas têm início nas flores mas podem continuar fora delas e durar até 20 minutos. O casal pode abandonar uma flor, voar, pousar em outra e continuar em posição de cópula. Uma vez em outra flor, a fêmea continua coletando pólen. Fêmeas marcadas foram observadas copulando, pelo menos, duas vezes em um dia. Os machos podem ainda discriminar flores de alta e pequena atratividade às fềmeas inspecionando as anteras das flores.

Os machos de $C$. anomalus podem se alimentar de néctar, quando estão nas flores esperando as fềmeas. Quando dois machos de $C$. anomalus estão presentes na mesma flor, eles podem apresentar comportamento agressivo um em relação ao outro. Contudo, parece que o macho de C. anomalus não apresenta agressividade contra macho de outra espécie de abelha, quando ambos se acham na mesma flor.

Neste estudo foi observado que o pico de visitas das fêmeas de C. anomalus ocorreu um pouco antes que o pico de visitas dos machos. Em Nomadopsis puellae (Cockerell, 1933) (Andrenidae, Panurginae) as fêmeas começam a forragear no início da manhã (THORNHILl \& ALCOCK 1983). Essa atividade dura, aproximadamente, até as 11:00 e 13:00 horas. No início da manhã, os machos podem copular várias vezes, sendo a duração das cópulas muito pequena. Com o passar do tempo, o número de machos procurando fêmeas aumenta. Esses machos copulam com poucas fêmeas, sendo a duração das cópulas maiores que no início da manhã. No final da manhã, uma fêmea que coletou suficiente quantidade de alimento poderia terminar o provisionamento de células em seu ninho e ovipor. Devido ao fenômeno de precedência de espermatozóides, embora sua ocorrência seja discutível nas abelhas (EICKWORT \& GINSBERG 1980), o último macho que copula com uma fêmea poliândrica poderia ser beneficiado, reprodutivamente. Esse modelo explica porque os machos seriam mais ativos no fim da manhã e porque o pico de atividade de machos de $C$. anomalus ocorre um pouco mais tarde que o das fêmeas.

Para C. anomalus a pequena sobreposição com M. cnecomala no horário de visitas e nas espécies de plantas visitadas deve ser muito vantajosa, principalmente, pelo fato das flores serem usadas por esta espécie não apenas como fonte de alimento mas, também, como sítios de cópula. Se fêmeas e machos de C. anomalus, tal como deve ocorrer com $C$. petunae, são capazes de detectar a quantidade de recursos disponíveis nas flores, um grande número de visitas nelas realizadas por outras abelhas poderia diminuir a quantidade de néctar e pólen disponível, tornando-as pouco atrativas, o que poderia resultar num menor período de atividade de fêmeas nessas flores e, portanto, numa menor ocorrência de acasalamentos. 
AGRADECIMENTOS. Ao Pe Jesus Santiago Moure (Departamento de Zoologia, UFPR) pela identificação das abelhas. A Olinda L. Bueno (Fundação Zoobotânica do Rio Grande do Sul) pela identificação das plantas. A Helena C. de Morais, Fernando A. da Silveira, José Ricardo Cure, Gabriel A. de Melo e Evaldo F. Vilela pelas discussões, sugestões e críticas. A Milene Faria Vieira e Gilmar Valente (Departamento de Botânica da UFV) pelo empenho no preparo do material botânico para identificação. A Arlete A. Soares e Marco A. Costa pelo auxílio nas coletas de abelhas.

\section{REFERÊNCIAS}

Allen-Wardell, G.; P. Bernhardt; R. Bitner.; A. Burquez; S. Buchmann; J. Cane; P.A. Cox; P. Feinsinger; M. Ingram; D. Inouye; C.E. Jones; K. Kennedy; P. Kevan; H. Koopowitz; R. Medellin; S. Medellin-Morales \& G.P. NABHAN. 1998. The potential consequences of pollinator declines on the conservation of biodiversity and stability of food crop yields. Conserv. Biol. 12 (1): 8-17.

Alves-DOS-SANTOS, I. 1999a. Abelhas e plantas meliferas da mata atlântica, restinga e dunas do litoral norte do estado do Rio Grande do Sul, Brasil. Revta bras. Ent. 43 (3/4): 191-223.

-1999b. Aspectos morfológicos e comportamentais dos machos de Ancyloscelis Latreille (Anthophoridae, Apoidea). Revta bras. Zool. 16 (Supl. 2): 37-43.

ARmbruster, W.S. \& A.L. Herzig. 1984. Partitioning and sharing of pollinators by four sympatric species of Dalechampia (Euphorbiaceae) in Panama. Ann. Missouri Bot. Gard. 71: 1-16.

BAKER, H.G. 1974. The evolution of weeds. Ann. Rev. Ecol. Syst. 5: 1-23.

BAWA, K.S. 1983. Patterns of flowering in tropical plants, p. 394-410. In: C.E. JoNES \& R.J. LITTLE (Eds). Handbook of experimental pollination biology. New York, Scientific and Academic Editions, $558 \mathrm{p}$.

BuCHManN, S.L. 1996. Competition between honeybees and native bees in the Sonoran Desert and global bee conservation issues, p. 125-142. In: A. MATHESON; S.L. BuCHMAnN; C. O'ToOle; P. WeSTRICH \& I.H. Wir.tiams (Eds). The conservation of bees. London, Academic Press, 254p.

BuchmanN, S.L. \& G.P. NABHAN. 1996. The forgotten pollinators. Washington, D.C., Island Press, $292 \mathrm{p}$.

BurRIL, M. \& A. DieTz. 1981. The response of honeybees to variation in solar radiation and temperature. Apidologie 12 (4): 319-328.

CAMARGO, J.M.F. \& M. MAZUCATO. 1984. Inventário da apifauna e flora apícola de Ribeirão Preto, SP, Brasil. Dusenia, Curitiba, 14: 55-87.

CAMPBELL, D.R. 1985a. Pollen and gene dispersal: the influences of competition for pollination. Evolution 39: 418-431.

-1985b. Pollinator sharing and seed set of Stellaria pubera: competition for pollination. Ecology 66 (2): 544-553.

- 1986. Predicting plant reproductive success from models of competition for pollination. Oikos 47: 257-266.

CAmpBell, D.R. \& A.F. MotTEN. 1985. The mechanism of competition for pollination between two forest herbs. Ecology 66 (2): 554-563.

CARPENTER, F.L. 1979. Competition between hummingbirds and insects for nectar. Amer. Zool. 19: $1105-1114$.

Cousens, R. \& M. Mortimer. 1995. Dynamics of weed populations. Cambridge, Cambridge Univ. Press, 332p.

CREPET, W.L. 1983. The role of insect pollination in the evolution of the angiosperms, p. 29-50. In: L. ReAl (Ed.). Pollination biology. London, Academic Press, 338p.

CURE, J.R. \& D. WitTMANN. 1990. Callonychium petuniae, a new panurgine bee species (Apoidea, Andrenidae), oligolectic on Petunia (Solanaceae). Stud. Neotrop. Fauna Environ. 25 (3): 153-156.

Cure, J.R.; M. Thiengo; F.A. Silveira \& L.B. RochA. 1992. Levantamento da fauna de abelhas 
silvestres na "Zona da Mata" de Minas Gerais. III. Mata secundária na região de Viçosa (Hymenoptera, Apoidea). Revta bras. Zool. 9 (3/4): 223-239.

Cure, J.R.; G.S. Bastos Filho; M.J.F. DE Oliveira \& F.A dA Silveira. 1993. Levantamento de abelhas silvestres na Zona da Mata de Minas Gerais. I - Pastagem na região de Viçosa (Hymenoptera, Apoidea). Revta Ceres, Viçosa, 40 (228): 131-161.

EICKWORT, G.C. \& H.S. GinsBerg. 1980. Foraging and mating behavior in Apoidea. Ann. Rev. Ecol. Syst. 25: 421-446.

Estes, J.R. \& R.W. Thorp. 1975. Pollination ecology of Pyrrhopappus carolinianus (Compositae). Amer. Jour. Bot. 62 (2): 148-159.

EwUsIE, J.Y. 1972. Preliminary studies on the floral mechanism of Sida stipulata. Jour. West African Sci. Assoc. 17 (1): 11-18.

FAegri, K. \& L. VAN DER PIJL. 1979. The principles of pollination ecology. Oxford, Pergamon Press, $3^{\text {rd }}, 291 p$.

FEINSINGER, P. 1987. Approaches to nectarivore-plant interactions in the New World. Revista Chileana de Historia Natural 60: 285-319.

FryXlLL, P.A. 1988. Malvaceae of Mexico. Syst. Botany Monographs 25: 1-475.

GinsBERG, H.S. 1983. Foraging ecology of bees in an old field. Ecology 1: 165-175.

GIORGINI, J.F. \& A.B. GuSMAN. 1972. A importância das abelhas na polinização, p. 155-214. In: J.M.F.

CAMARgo (Ed.). Manual de Apicultura. São Paulo, Editora Agronômica Ceres, 252p.

Golfari, L. 1975. Zoneamento ecológico do Estado de Minas Gerais para reflorestamento. Belo Horizonte, Projeto de Desenvolvimento e Pesquisa Florestal, PNUD/FAO/IBDF, 65p.

GOTTSBERGER, G. 1972. Blütenbiologische Beobachtungen an brasilianischen Malvaceen. II. Österr. Bot. Z. 120: 439-509.

1986. Some pollination strategies in Neotropical savannas and forests. PI. Syst. Evol. 152: 29-45.

HEINRICH, B. 1976a. Resource partitioning among some eusocial insects: bumblebees. Ecology 57: 874-889.

. 1976b. Flowering phenologies: bog, woodland, and disturbed habitats. Ecology 57: 890-899.

HeINRICH, B. \& P.H. RAVEN. 1972. Energetics and pollination ecology. Science 176: 597-602.

HEITHAUS, E.R. 1974. The role of plant-pollinator interactions in determining community structure. Ann. Missouri Bot. Gard 61: 675-691.

-1979a. Flower visitation records and resource overlap of bees and wasps in northwest Costa Rica. Brenesia 16: 9-52.

1979b. Community structure of neotropical flower visiting bees and wasps: diversity and phenology. Ecology 60: 190-202.

INOUYE, D. 1978. Resource partitioning in bumblebees: experimental studies of foraging behavior. Ecology 4: 672-678.

JOHNSON, L.K. 1983. Foraging strategies and the structure of stingless bee communities in Costa Rica, p. 31-58. In: P. JAISSON (Ed.). Social insects in the tropics. V.I. Paris, Universite Paris-Nord, $280 \mathrm{p}$.

JOHNSON, L.K. \& S.P. HUBBELL. 1974. Aggression and competition among stingless bees: field studies. Ecology 55: 120-127.

-1975. Contrasting foraging strategies and coexistence of two bee species on a single resource. Ecology 56: 1398-1406.

KEPHART, S.R. 1983. The partitioning of pollinators among three species of Asclepias. Ecology 64 (1): 120-133.

LACK, A.J. 1982a. Competition for pollinators in the ecology of Centaurea scabiosa L. and Centaurea nigra L. I. Variation in flowering time. New Phytol. 91: 297-308.

1982b. Competition for pollinators in the ecology of Centaurea scabiosa L. and Centaurea nigra L. III. Insect visits and the number of successful pollinations. New Phytol. 91: 321-339.

1982c. The ecology of flowers of chalk grassland and their insect pollinators. Jour. Ecol. 


$$
\text { 70: 773-790. }
$$

LAROCA, S. 1970. Notas adicionais sobre a bionomia das espécies de Melissoptila que ocorrem nas vizinhanças de Curitiba, Paraná. (Hymenoptera, Apoidea). Bol. Univ. Fed. Paraná, Zoologia, 15: 293-306.

LeITÃo Filho, H. DE F.; C. ARANHA \& O. BACCHI. 1982. Plantas invasoras de culturas. I. Campinas, Instituto Campineiro de Ensino Agrícola, 291p.

LINSLEY, E.G. 1978. Temporal patterns of flower visitation by solitary bees with particular reference to the southwestern United States. Jour. Kansas Entomol. Soc. 51 (4): 531-546.

LOMNICKI, A. 1988. Population ecology of individuals. Princeton, New Jersey, Princeton University Press, 223p.

LoRENZI, H. 1982. Plantas daninhas do Brasil. Nova Odessa, Edição do Autor, 425p.

LUDWIG, J.L. \& J.F. REYNOLDS. 1988. Statistical ecology: a primer on methods and computing. New York, John Wiley \& Sons, 337p.

MACARTHUR, R.H. 1972. Geographical ecology: patterns in the distribution of species. New York, Harper \& Row, 269p.

Monteiro-Filho, H.C. 1936. O gênero Sida: revisão das espécies brasileiras. Monographia das Malvaceas Brasileiras. I. Rio de Janeiro, Ministério da Agricultura, 56p.

Murray, K.G.; P. Feinsinger; W.H. Busby; Y.B. LinhArT; J.H. BeACH \& S. Kinsman. 1987. Evaluation of character displacement among plants in two tropical pollination guilds. Ecology 68 (5): 1283-1293.

NefF, J.L. \& B.B. Simpson. 1993. Bees, pollination systems and plant diversity, p. 143-167. In: J. LASALLE \& I.D. GAULD (Eds). Hymenoptera and biodiversity. Wallingford, C.A.B. International, $348 \mathrm{p}$.

PiankA, E.R. 1973. The structure of lizard communities. Ann. Rev. Ecol. Syst. 4: 53-74.

Pleasants, J.M. 1980. Competition for bumblebee pollinators in Rocky Mountain Plant Communities. Ecology 6: 1446-1459.

RANTA, E. 1982. Species structure of North European bumblebee communities. Oikos 38: 202- 209.

Ranta, E.; H. LundBerg \& I. Teras. 1981. Patterns of resource utilization in two Fennoscandian bumblebee communities. Oikos 36: 1-11.

RATHCKE, B. 1983. Competition and facilitation among plants for pollination, p. 305-329. In: L. REAL

(Ed.). Pollination biology. London, Academic Press, 338p.

RicKLEFS, R.E. 1990. Ecology. New York, W.H. Freeman \& Company, $3^{\text {rd }}, 896 \mathrm{p}$.

RouBIK, D.W. 1978. Competitive interactions between neotropical pollinators and africanized honeybees. Science 201: 1030-1032.

-1981. Comparative foraging behavior of Apis mellifera and Trigona corvina (Hymenoptera: Apoidea) on Baltimora recta (Compositae). Rev. Biol. Trop. 2: 177-183.

- 1982. Ecological impact of africanized honeybees on native neotropical pollinators, $\mathrm{p}$. 233-247. In: P. JAISSON (Ed.). Social insects in the tropics. V. I. Paris, Université Paris-Nord, 280p.

RoubiK, D.W. \& S.L. BuCHMANN. 1984. Nectar selection by Melipona and Apis mellifera (Hymenoptera: Apidae) and the ecology of nectar intake by bee colonies in a tropical forest. Oecologia 61: 1-10.

ROUGHGARDEN, J. 1979. Theory of population genetics and evolutionary ecology: an introduction. New York, MacMillan, 634p.

Rozen JR., J.G. 1989. Life history studies of the "primitive" Panurgine bees (Hymenoptera: Andrenidae: Panurginae). Amer. Mus. Novit. 2962: 1-27.

Siegel, S. \& N.J. CAStellAN JR. 1988. Nonparametric statistics for the behavioral sciences. New York, McGraw-Hill, 399p.

SilveirA, F.A.; L.B. DA RochA; J.R. Cure \& M.J.F. DE OliveirA. 1993. Abelhas silvestres (Hymenoptera, Apoidea) da Zona da Mata de Minas Gerais. II. Diversidade, abundância e fontes de alimento em uma pastagem abandonada em Ponte Nova. Revta bras. Ent. 37 (3): 595-610.

Simpson, B.B. \& J.L. Neff. 1981. Floral rewards: alternatives to pollen and nectar. Ann. Missouri Bot. Gard. 68: 301-322. 
Stanley, R.G. \& H.F. Linskens. 1974. Pollen: biology, biochem istry, management. Berlin, Springer, $307 \mathrm{p}$.

STEBBins, G.L. 1965. Colonizing species of the native California flora, p. 173-195. In: H.G. BAKER \& G.L. StebBins (Ed.). The genetics of colonizing species. New York, Academic Press, 588p.

StepHenson, A.G. \& R.I. BerTin. 1983. Male competition, female choice, and sexual selection in plants, p. 109-149. In: L. REAL (Ed.). Pollination biology. London, Academic Press, 338p.

THOMSON, J.D. \& B.A. THOMSON. 1992. Pollen presentation and viability schedules in animal-pollinated plants: consequences for reproductive success, p. 1-24. In: R. WYATT (Ed.). Ecology and evolution of plant reproduction. New York, Chapman \& Hall, 397p.

Thornhili., R. \& J. At.COCK. 1983. The evolution of insect mating systems. Cambridge, Massachusetts, Harvard Univ. Press, 547p.

UgBorogiro, R.E. 1980. Floral mechanism as an aid to the classification of the Sida rhombifolia complex (Malvaceae) in Nigeria. Bulletin I'I.F.A.N., sér. A, 1: 107-121.

VAlverde, O. 1958. Estudo regional da Zona da Mata de Minas Gerais. Revta bras. Geogr. 1: 3-82.

WiLliams, N.H. \& C.H. DodSON. 1972. Seletive attraction of male euglossine bees to orchid floral fragrances and its importance in long distance pollen flow. Evolution 26: 84-95.

WittMann, D.; R. RadtKe; J.R. Cure \& M.T. Schifino-WittMann. 1990. Coevolved reproductive strategies in the oligolectic bee Callonychium petuniae (Apoidae, Andrenidae) and three purple flowered Petunia species (Solanaceae) in southern Brazil. Z. zool. Syst. Evolut. forsch. 28: 157-165.

ZAVORTINK, T.J. 1972. A new subgenus and species of Megandrena from Nevada, with notes on its foraging and mating behavior (Hymenoptera, Andrenidae). Proc. Ent. Soc. Wash. 1: 61-77.

Zimmerman, M. 1984. Reproduction in Polemonium: a five year study of seed production and implications for competition for pollinator. Oikos 42: 225-228.

Recebido em 27.V.1999; aceito em 25.VIII.2000. 